\title{
The impact of ignition system damage on the emission of toxic substances in a spark-ignition internal combustion engine
}

The article discusses the impact of ignition system damage on the emission of toxic subcategories in a spark-ignition internal combustion engine. The aim of the work was to develop an analytical model of ignition system diagnostics, test performance and comparative analysis of the results of simulations and experiments. The model developed allows to analyse the basic parameters of the ignition system affecting the content of toxic substances in the exhaust. Experimental tests were carried out using the MAHA MGT5 exhaust gas analyser for four different combustion engines fueled with petrol at various operating conditions. During the tests, the content of toxic substances in the exhaust gas of a properly working engine and the engine working with damage to the ignition system were registered. The tests will be used to assess the impact of the damage of the spark-ignition engine on the emission of individual components of toxic fumes.

Key words: spark-ignition internal combustion engine, emission of toxic substances, exhaust standards, ignition system defects, diagnostics

\section{Introduction}

The unfavourable influence of the automotive industry and road transport on the state of the environment is felt in Poland as one of the pressing problems to be solved. The ever more modern efficiency and ecology solutions introduced in vehicles are offset by the constantly increasing number of vehicles on the road, and the amount of toxic exhaust components released into the atmosphere [9].

Protection of the natural environment, carried out for a long time, has gained particular importance in recent years. The two basic reasons behind it are the rapid, uncontrolled progress in the development of the automotive industry and the distribution of emission sources in urban and industrial areas.

Regardless of the type of engines driving modern vehicles, three fuundamental factors are taken into account in their evaluation $[1,11]$ :

- fuel consumption,

- content of toxic substances,

- engine flexibility.

Meeting the consequent conditions is a challenge requiring significant financial outlays to carry out research on solutions in manufactured vehicles. It is assumed that the greatest environmental impact in a vehicle in terms of harmfulness comes from its engine. It is impossible to develop an engine control programme that would ensure zero emissions.

Exhaust emissions tests in terms of toxicity are performed on new engines to meet the approval conditions in accordance with standards that have varying global emission limits in individual years. European emission limits are defined by Euro 1-6 standards for cars and trucks. These standards concern the emission of four basic exhaust gas components: $\mathrm{CO}, \mathrm{CO}_{2}, \mathrm{HC}, \mathrm{NO}_{\mathrm{x}}$ and $\mathrm{PM}$ particulate matter. Analysis of spark-ignition internal combustion engines requires a detailed examination from the point of view of the impact of the ignition system parameters on exhaust emissions. The ignition parameters affecting the emission of toxic substances include the ignition advance angle, the spark discharge energy and the distance between the spark electrodes $[3,8,10]$.

\section{Analysis of the impact of ignition system parameters on the emission of toxic substances}

Depending on the composition of the fuel and air mixture, the change in the ignition advance angle affects the temperature of the combustion process. The maximum engine power is obtained at the highest temperatures, providing a rich mixture to the combustion chamber. In the case of poor mixtures it is necessary to increase the ignition advance angle, which is associated with a change in the content of carbon monoxide, hydrocarbons and nitrogen oxides in the exhaust.

\subsection{Ignition advance angle}

By making changes of the ignition advance angle in relation to the optimum value, the pressure and temperature in the combustion chamber are reduced, which reduces the amount of hydrocarbons. This is also connected with the increase of temperature during the expansion and discharge stroke, which causes the combustion of toxic substances in the exhaust system after the combustion process [12].

Ignition timing retardation reduces the amount of nitrogen oxides in the exhaust fumes for lean and stoichiometric mixtures. This is due to the lower combustion temperature, which is the result of a partial transfer of the combustion process to the expansion stroke.

\subsection{Energy of the spark discharge}

The energy of the spark discharge has a large impact on the emission of toxic substances, which should be greater than the energy of ignition for a given fuel. The discharge energy is the product of the voltage on the spark plug, the intensity of the discharge current and the duration of the discharge. 
In the case of rich mixtures $(\lambda<1)$, the current intensity and the spark discharge time have no effect on the emission of hydrocarbons, nitrogen oxides and unit fuel consumption. When using a lean mixture $(\lambda>1)$ it is necessary to generate a higher spark current and a longer discharge time $[2,7]$.

\subsection{The distance between the candle electrodes}

The emission of toxic substances depends on the way the flame front propagates in the cylinder chamber, the location of the spark plug in the head and the distance between the electrodes. The position of the candle close to the cylinder wall increases the hydrocarbon emission associated with the flame extinguishing effect. A very similar phenomenon occurs when the diameter of the centre electrode and the gap between the electrodes increase.

\section{Model of the high voltage course in the ignition system}

The development of the voltage waveform model involves the use of simplifications. Assumptions are made about its linearity, and sometimes also stationarity. In stationary objects, the reaction depends only on the input signal and there are no changes in their properties due to the passage of time.

The development of an analytical model of a high voltage course requires taking into account all parameters and determining the mutual relationships between them. The obtained equations describe the dependencies between particular sizes of the ignition system.

The electric scheme of the ignition system is shown and described in Fig. 1 [6].

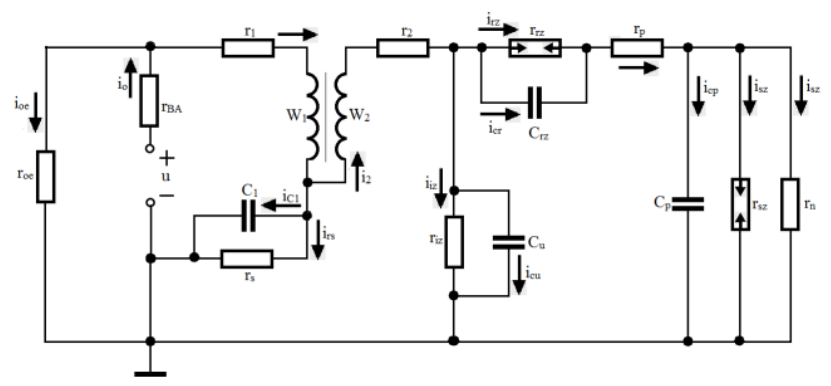

Fig. 1. Electrical diagram of the ignition system

where: $r_{\mathrm{oe}}-$ resistance of electric energy receivers, $r_{\mathrm{BA}}-$ internal resistance of the battery, $r_{1}=r_{w a r}+r_{w 1}-$ total resistance of the primary winding of the ignition coil, $\mathrm{r}_{\mathrm{s}}-$ resistance in the connecting circuit, $r_{z}=r_{w z}+r_{w}$ - resistance of the secondary coil of the ignition coil, $r_{\mathrm{iz}}$ - insulation resistance, $r_{r z}-$ ignition distributor resistance, $r_{p}$ - resistance of high-voltage wires, $r_{\mathrm{sz}}$ - resistance of the gap between the spark plug electrodes, $r_{n}$ - carbon deposit resistance on the spark plug, $\mathrm{C}_{1}-$ capacitor capacity, $\mathrm{C}_{\mathrm{u}}$ - capacity of the secondary winding of the ignition coil, $\mathrm{C}_{\mathrm{rz}}$ - ignition distributor capacity, $\mathrm{C}_{\mathrm{p}}=\mathrm{C}_{\mathrm{pw}}+\mathrm{C}_{\mathrm{sz}}$ - the capacity of wires and spark plugs, $\mathrm{W}_{1}$ - number of turns of the primary winding of the ignition coil, $\mathrm{W}_{2}$ - number of windings of the secondary coil of the ignition coil, $\mathrm{U}$ - battery voltage.

The electrical diagram of the ignition system shown in Figure 1 is described by the following equations:

$$
\begin{aligned}
& \mathrm{U}=\mathrm{i}_{\mathrm{o}} \cdot \mathrm{r}_{\mathrm{BA}}+\mathrm{i}_{1} \cdot \mathrm{r}_{1}+\mathrm{W}_{1} \cdot \mathrm{S} \cdot \frac{\mathrm{dB}}{\mathrm{dt}}+\mathrm{u}_{\mathrm{C} 1} \\
& \mathrm{U}=\mathrm{i}_{\mathrm{o}} \cdot \mathrm{r}_{\mathrm{BA}}+\mathrm{i}_{\mathrm{O}_{\mathrm{e}}} \cdot \mathrm{r}_{\mathrm{o}_{\mathrm{e}}} \\
& \mathrm{i}_{\mathrm{o}}=\mathrm{i}_{1}+\mathrm{i}_{\mathrm{o}_{\mathrm{e}}} \\
& \mathrm{i}_{1}=\mathrm{i}_{\mathrm{c} 1}+\mathrm{i}_{\mathrm{rs}}+\mathrm{i}_{2} \\
& \mathrm{H} \cdot \mathrm{l}=\mathrm{i}_{1} \cdot \mathrm{W}_{1}+\mathrm{i}_{2} \cdot \mathrm{W}_{2} \\
& \mathrm{H}=\mathrm{A} \cdot \mathrm{B} \\
& \mathrm{u}_{\mathrm{c} 1}=\mathrm{i}_{\mathrm{rs}} \cdot \mathrm{r}_{s} \\
& r_{s}=\left\{\begin{array}{c}
r_{s 0}-\text { open circuit } \\
r_{s 1}-\text { compact circuit }
\end{array}\right. \\
& \mathrm{u}_{\mathrm{c} 1}=\frac{1}{\mathrm{C}_{1}} \int \mathrm{i}_{\mathrm{c} 1} \cdot \mathrm{dt}+\mathrm{u}_{\mathrm{c} 1}(0) \\
& \mathrm{W}_{2} \cdot \mathrm{S} \cdot \frac{\mathrm{dB}}{\mathrm{dt}}+\mathrm{i}_{2} \mathrm{r}_{2}+\mathrm{u}_{\mathrm{cu}}+\mathrm{u}_{\mathrm{c} 1}=0 \\
& \mathrm{i}_{2}=\mathrm{i}_{\mathrm{iz}}+\mathrm{i}_{\mathrm{cu}}+\mathrm{i}_{\mathrm{p}} \\
& \mathrm{i}_{\mathrm{p}}=\mathrm{i}_{\mathrm{rz}}+\mathrm{i}_{\mathrm{cr}}=\mathrm{i}_{\mathrm{cp}}+\mathrm{i}_{\mathrm{sz}}+\mathrm{i}_{\mathrm{n}} \\
& \mathrm{u}_{\mathrm{cu}}=\frac{1}{\mathrm{C}_{\mathrm{u}}} \int \mathrm{i}_{\mathrm{cu}} \mathrm{dt}+\mathrm{u}_{\mathrm{cu}}(0) \\
& \mathrm{u}_{\mathrm{cu}}=\mathrm{u}_{\mathrm{cr}}+\mathrm{i}_{\mathrm{p}} \cdot \mathrm{r}_{\mathrm{p}}+\mathrm{u}_{\mathrm{cp}} \mathrm{i}_{2}=\mathrm{i}_{\mathrm{iz}}+\mathrm{i}_{\mathrm{cu}}+\mathrm{i}_{\mathrm{p}} \\
& \mathrm{u}_{\mathrm{cu}}=\mathrm{i}_{\mathrm{iz}} \cdot \mathrm{r}_{\mathrm{iz}} \\
& \mathrm{u}_{\mathrm{cr}}=\frac{1}{\mathrm{C}_{\mathrm{rz}}} \int \mathrm{i}_{\mathrm{cr}} \mathrm{dt}+\mathrm{u}_{\mathrm{cr}}(0) \\
& \mathrm{u}_{\mathrm{cr}}=\mathrm{i}_{\mathrm{rz}} \cdot \mathrm{r}_{\mathrm{rz}} \\
& r_{r z}=\left\{\begin{array}{c}
r_{r z 0}-\text { without a spark } \\
r_{r z 1}-\text { with a spark }
\end{array}\right. \\
& \mathrm{u}_{\mathrm{cp}}=\frac{1}{\mathrm{C}_{\mathrm{p}}} \int \mathrm{i}_{\mathrm{cp}} \cdot \mathrm{dt}+\mathrm{u}_{\mathrm{cp}}(0) \\
& \mathrm{u}_{\mathrm{cp}}=\mathrm{i}_{\mathrm{sz}} \cdot \mathrm{r}_{\mathrm{sz}}=\mathrm{i}_{\mathrm{n}} \cdot \mathrm{r}_{\mathrm{n}}
\end{aligned}
$$

where: $\mathrm{S}$ - cross-sectional area of the ignition coil, B magnetic induction, $\mathrm{t}$ - time, $\mathrm{H}$ - intensity of the magnetic field, 1 - average length of the magnetic field lines, A constant.

Mathematical equations (1)-(20) describe the changes in the electrical size of the ignition system and the relationships between the various ignition systems.

Using the above mathematical equations and software in the LabView environment, a voltage waveform was generated on the coil's secondary winding shown in Fig. 2.

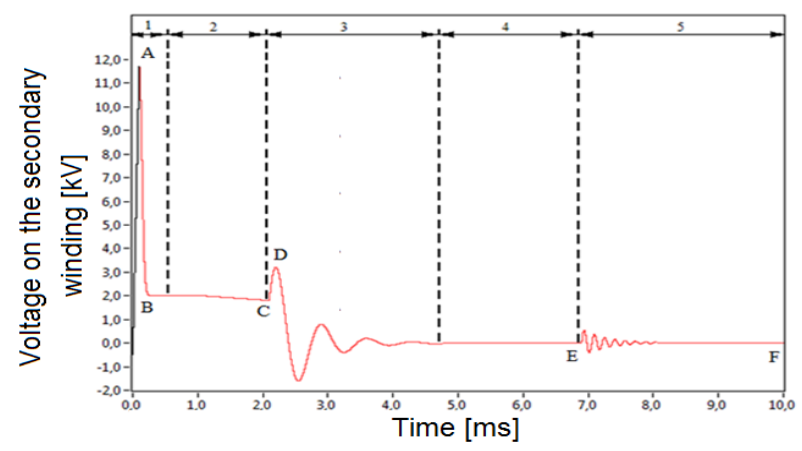

Fig. 2. The ignition signal on the secondary side is made with LabView software 
The course of the ignition voltage on the secondary side is made up of three characteristic sections:

- the section of spark operation, which includes the time interval "1" and "2",

- a transition period within the time interval "3" and "4",

- a short circuit which includes the course from the time interval "5".

When developing a model of the ignition voltage course on the secondary side, the following damage to the system was taken into account:

- the ignition voltage drop below $5 \mathrm{kV}$ in the event of a short-circuit in the ignition wire to the mass reflects damage to the spark plug or coil,

- an increase in the ignition voltage above $5 \mathrm{kV}$ in the event of a short-circuit in a single ignition wire reflects damage to the distributor or high-voltage cables,

- an increase in the ignition voltage above $5 \mathrm{kV}$ in the event of shorting all ignition wires reflects damage to the distributor or interruption of the ignition coil high voltage wire,

- increase in the ignition voltage above $12 \mathrm{kV}$ on selected cylinders reflects the increased inter-electrode gap, break in the high voltage circuit or uneven composition of the fuel-air mixture for individual cylinders.

The impact of the above failures on the course of the ignition voltage is shown in Figs 3-6, while the results of toxicity tests are presented in the author's publications $[4,5]$.

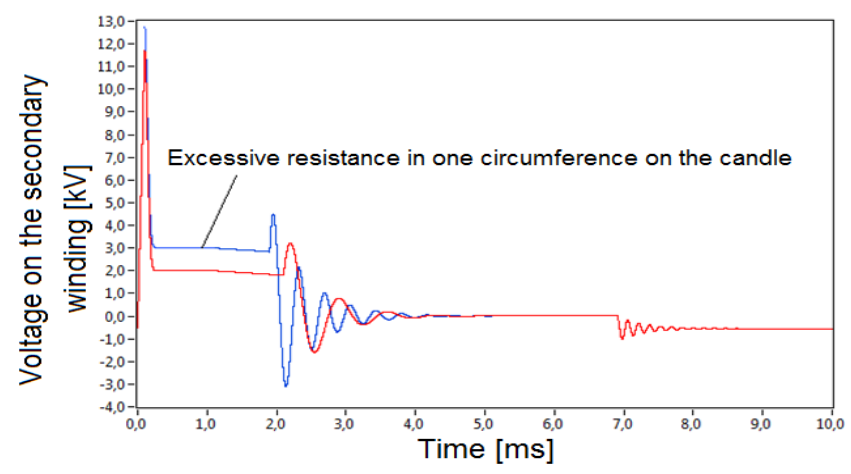

Fig. 3. Changes in the ignition voltage course on the secondary side in the event of shorting a single ignition wire to ground

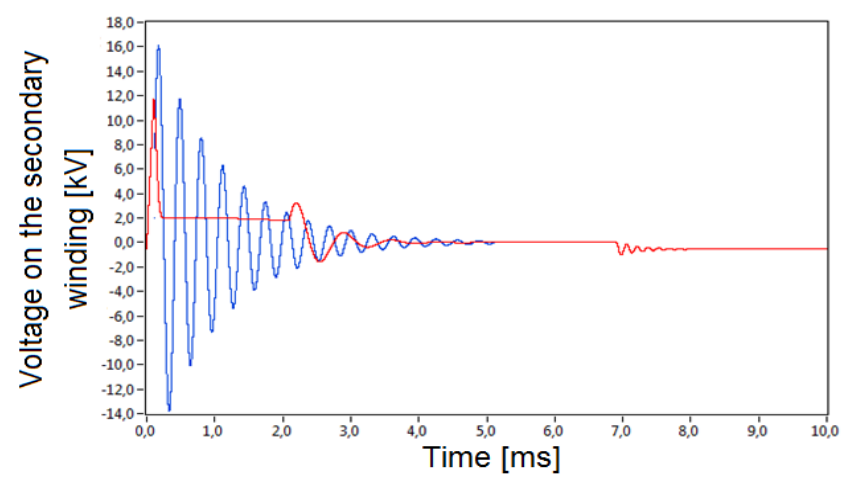

Fig. 4. Changes in the ignition voltage course on the secondary side in the event of a break in the spark plug circuit and no spark

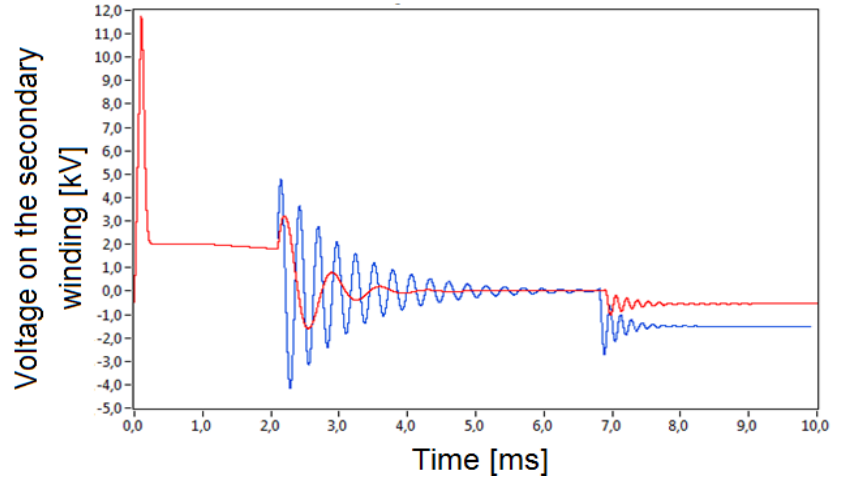

Fig. 5. Changes in the ignition voltage course on the secondary side in the event of a high voltage break in the circumference of the candle

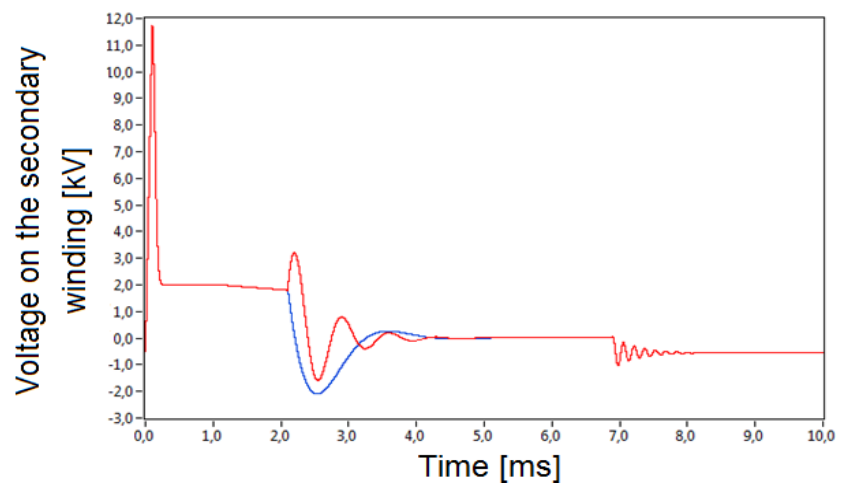

Fig. 6. Changes in the ignition voltage course on the secondary side in the case of shorting of the winding in the ignition coil or piercing of the capacitor

\section{Experimental research}

Tests were carried out for the BMW M10B18 (Fig. 7) and Fiat 1.1 (Fig. 8) internal combustion engine fueled with petrol. They were equipped with indirect MPI fuel injection and an electronic ignition system. The BMW M10B18 engine have mechanical ignition distributor and has not catalytic converter. The Fiat 1.1 engine has catalytic converter.

The use of FSA, KTS, MOT motor diagnosis allowed to register changes taking place during simulation of ignition system faults. In conjunction with the MAHA MGT5 analyser (Fig. 9), the emission of toxic substances to change parameters in electric circuits was registered.

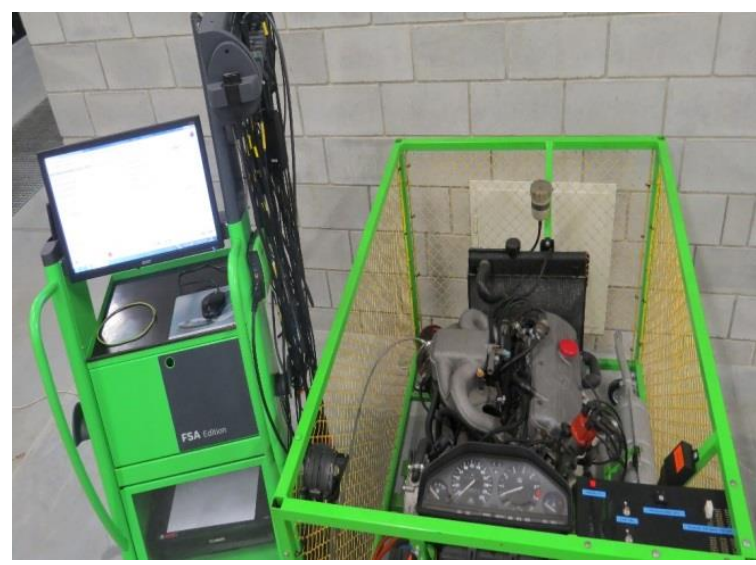

Fig. 7. Test stand of the BMW M10B18 engine. 


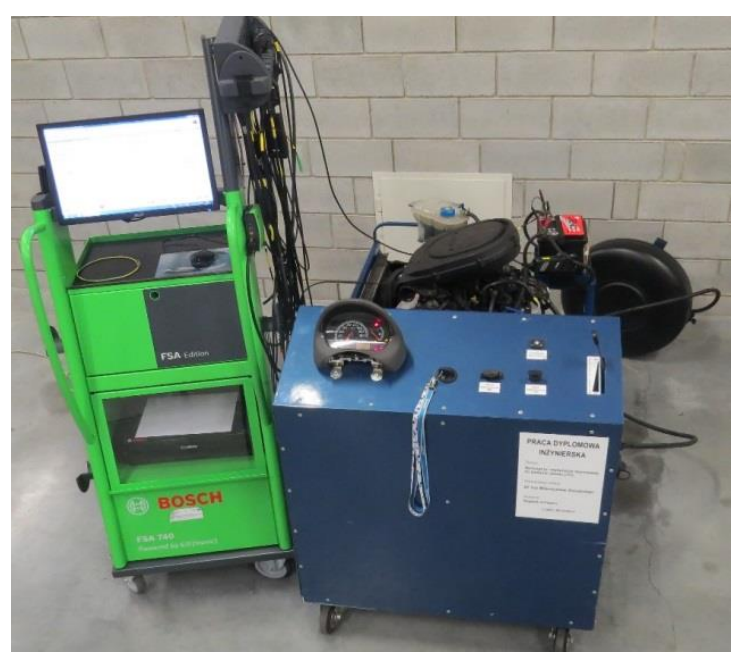

Fig.8. Test stand of the Fiat 1.1 engine

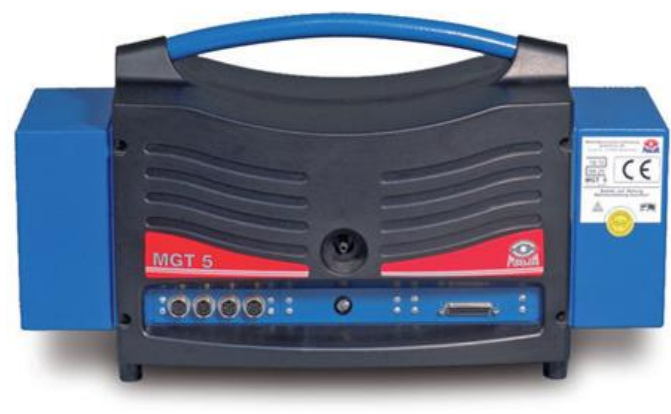

Fig. 9. MAHA MGT 5 exhaust gas analyzer

Ignition system tests including changes in electrical circuit parameters and toxicity included:

- determination of emission of correctly functioning spark-ignition engines,

- determination of changes in the composition of exhaust gases in the event of a lack of continuity in the circuit of one of the high voltage wires,

- to determine the toxicity of exhaust gases if the gap between the spark plug electrodes is reduced or increased,

- determination of toxicity of fumes in the event of a change in the location of the spark plug electrode,

- simulation of the phenomenon of switching off individual cylinders using the MOT 250 diagnoscope,

- control of the secondary circuit of the ignition system (full adaptation) by means of FSA 720.

Prior to the simulation of the ignition system faults, activities were carried out to check the correct operation of the engines and individual toxic components in the exhaust were registered. The gas analyzer probe was placed in the end of the exhaust tube.

- Tests carried out for a BMW M10B18 and Fiat 1.1 engines fueled with petrol:

- measurement of the content of nitrogen oxides in exhaust gas (Fig. 10 and Fig.16),

- measurement of the hydrocarbon content in the flue gas (Fig. 11 and Fig. 17),

- measurement of carbon dioxide content in flue gas (Fig. 12 and Fig. 18),
- measurement of the carbon monoxide content in the flue gas (Fig. 13 and Fig. 19),

- measuring the oxygen content in the exhaust gas (Fig. 14 and Fig. 20),

- measurement of the excess air ratio in the exhaust gas (Fig. 15 and Fig. 21).

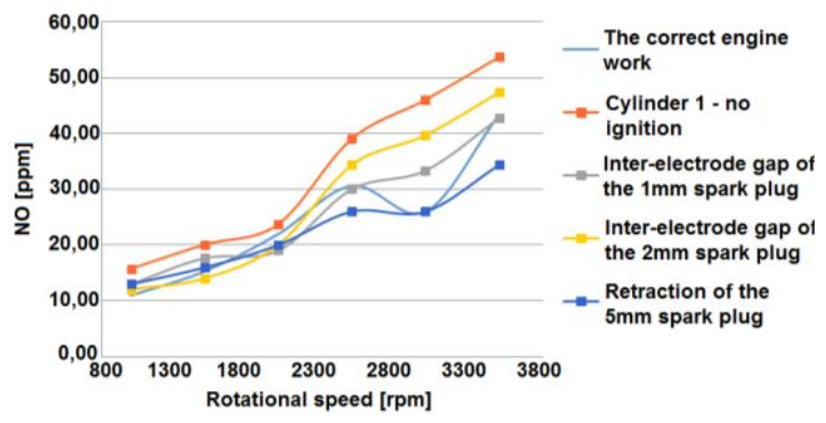

Fig. 10. The content of nitrogen oxides in the exhaust gas of the BMW M10B18 engine

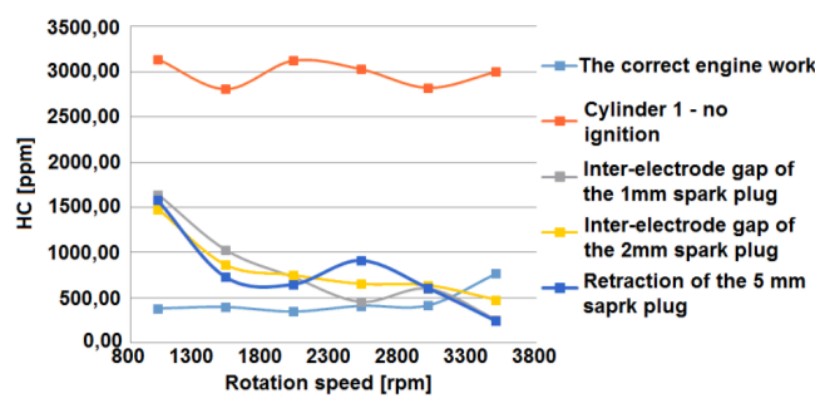

Fig. 11. The hydrocarbon content in the exhaust gas of the BMW M10B18 engine

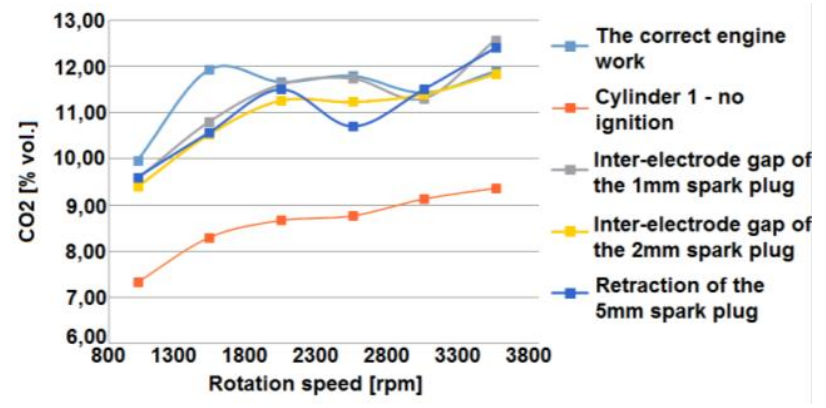

Fig. 12. The carbon dioxide content in the BMW M10B18 engine exhaust gas

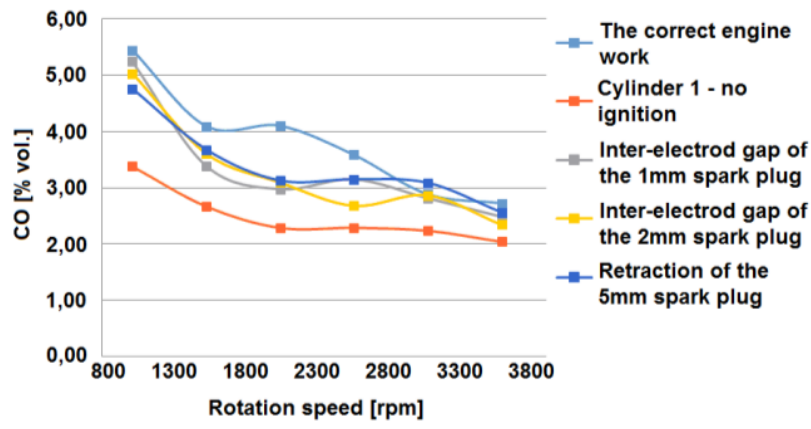

Fig. 13. The content of carbon monoxide in the exhaust gas of the BMW M10B18 engine 


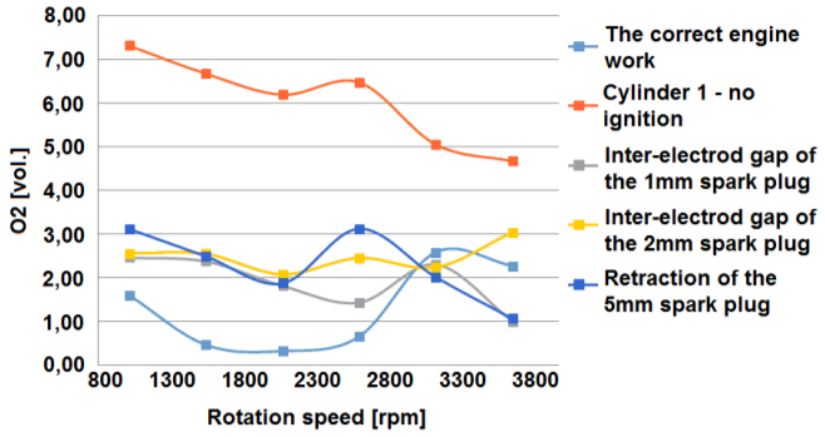

Fig. 14. The oxygen content in the exhaust gas of the BMW M10B18 engine

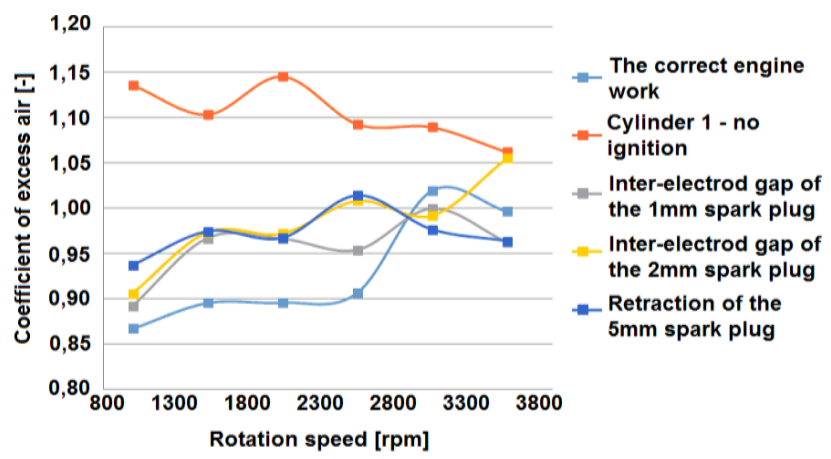

Fig 15. The value of the BMW M10B18 engine's excess air coefficient

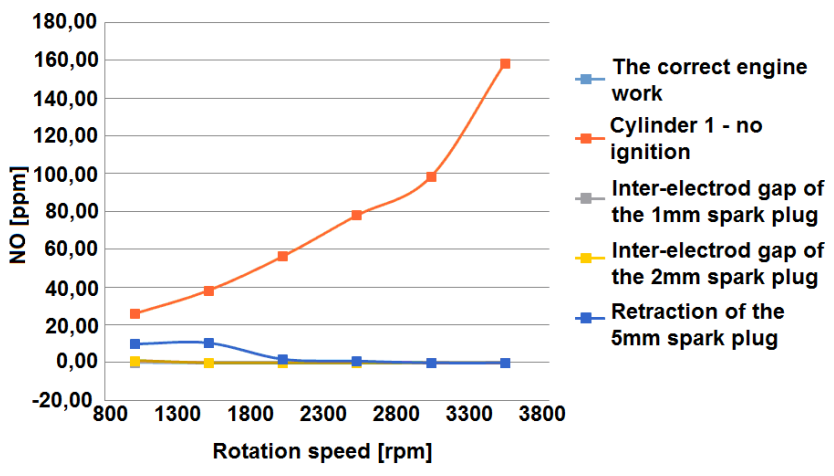

Fig. 16. The content of nitrogen oxides in the exhaust gas of the Fiat 1.1 engine

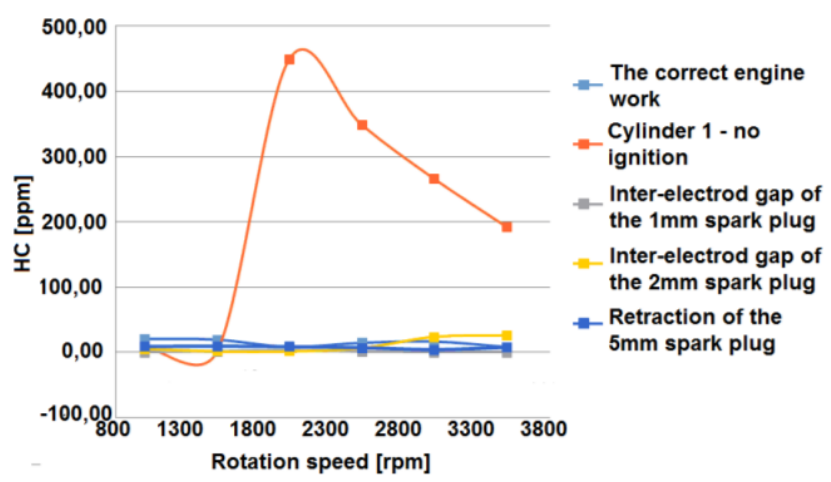

Fig. 17. The hydrocarbon content in the exhaust gas of the Fiat 1.1 engine

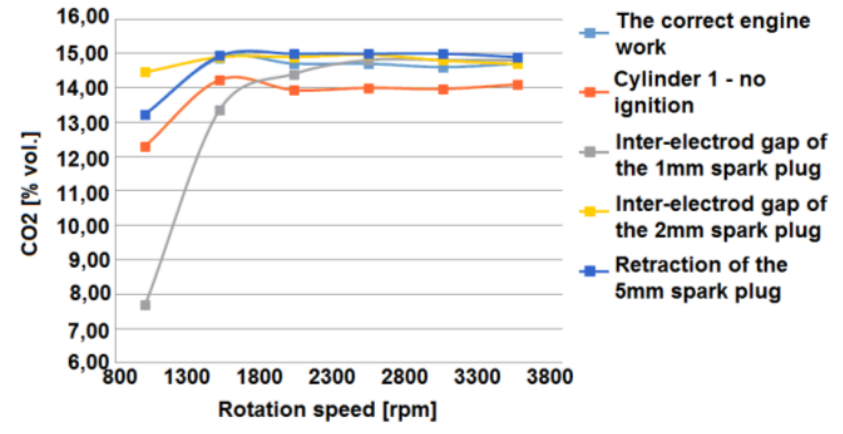

Fig. 18. The carbon dioxide content in the Fiat 1.1 engine exhaust gas

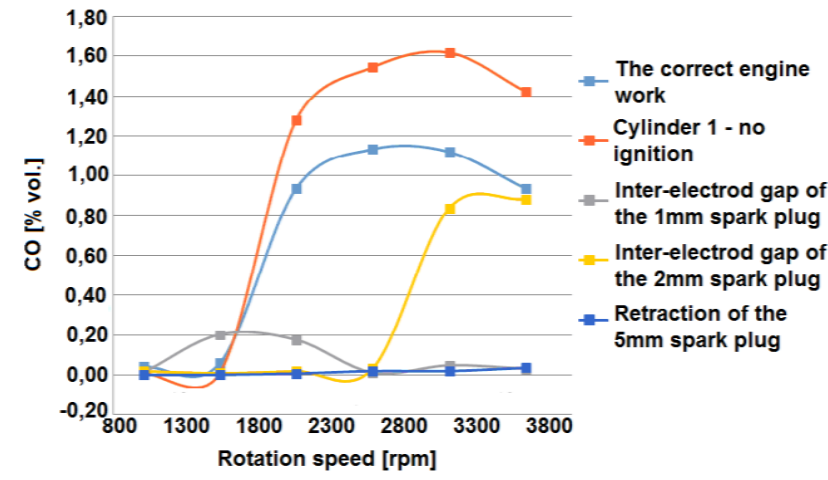

Fig. 19. The content of carbon monoxide in the exhaust gas of the Fiat 1.1 engine

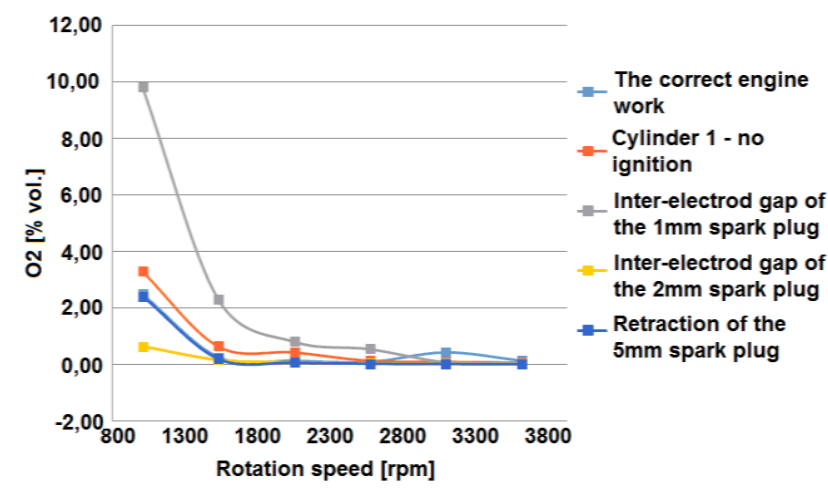

Fig. 20. The oxygen content in the exhaust gas of the Fiat 1.1 engine

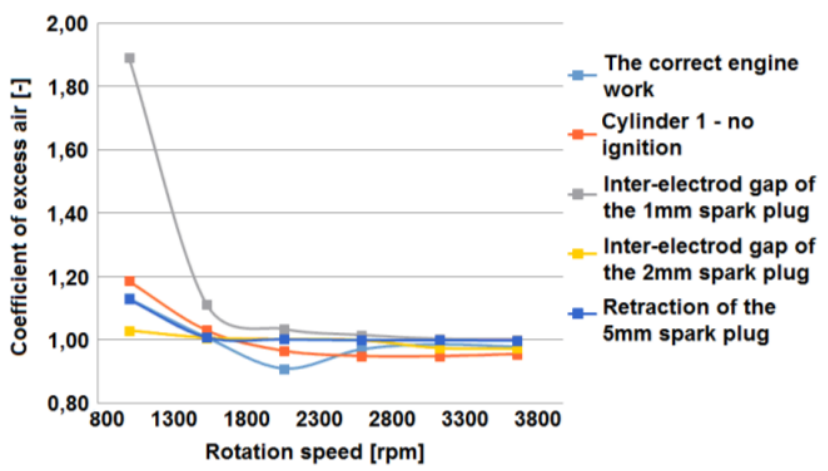

Fig. 21. The value of the Fiat 1.1 engine's excess air coefficient 


\subsection{Analysis of test results based on surface charts}

The mission graphs prepared in the rotational speed coordinate system make it easier to interpret the work of the engine and its components. The simulation of basic failures results in engine control changes through the correction of the fuel and air mixture, modification of the ignition advance angle and regulation of the exhaust gas recirculation valve. The settings forced in this way affect the combustion process and the amount of toxic substances emitted. Selected fault conditions occur only for specific engine operation parameters and individual atmospheric conditions.

Analysis of the results obtained allows to observe changes that could have occurred in the engine control in a given speed range for the selected damage.

On the basis of the tests performed, surface charts were developed to facilitate the analysis of results and to determine the dependence between individual engine parameters affecting the emissions of toxic substances. The surfaces created show the dependence of emissions of nitrogen oxides, hydrocarbons, carbon monoxide, carbon dioxide on the rotational speed and the effect of simulated ignition system damages on the toxicity of exhaust gases. The surfaces obtained allow to interpret the results of investigations of changes occurring during the combustion process, which are affected by the engine's operating parameters and the ignition systems used and their associated damage.

The surface charts for the emission of toxic substances for the BMW M10B18 and Fiat 1.1 petrol-fueled engines are shown in Figs 22-25.

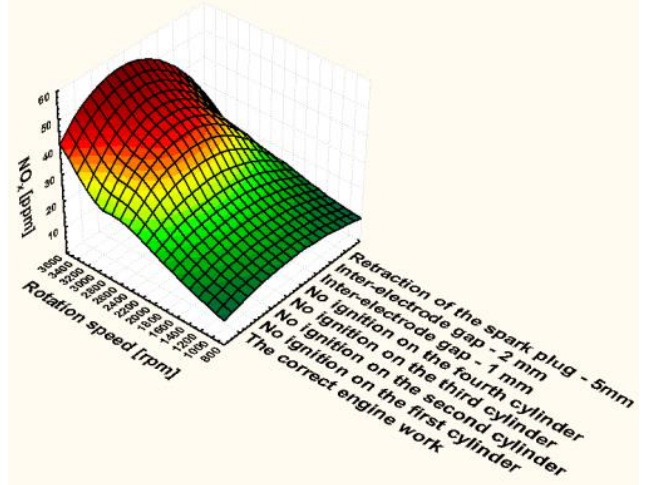

Fig. 22. The content of nitrogen oxides emitted by the BMW M10B18 petrol-powered engine

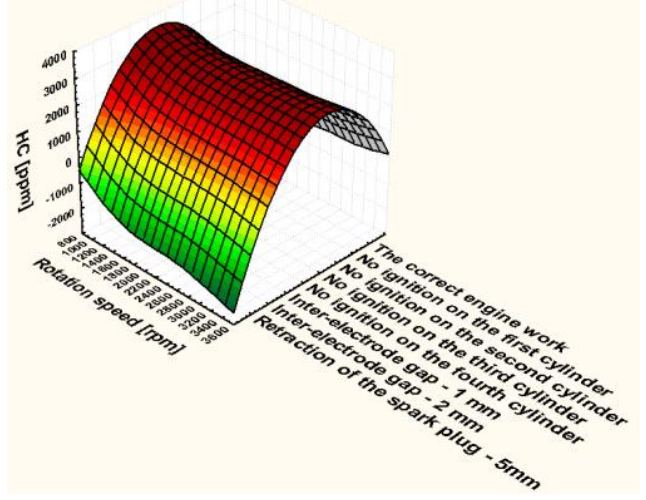

Fig. 23. The content of hydrocarbons emitted by the BMW M10B18 petrol-powered engine

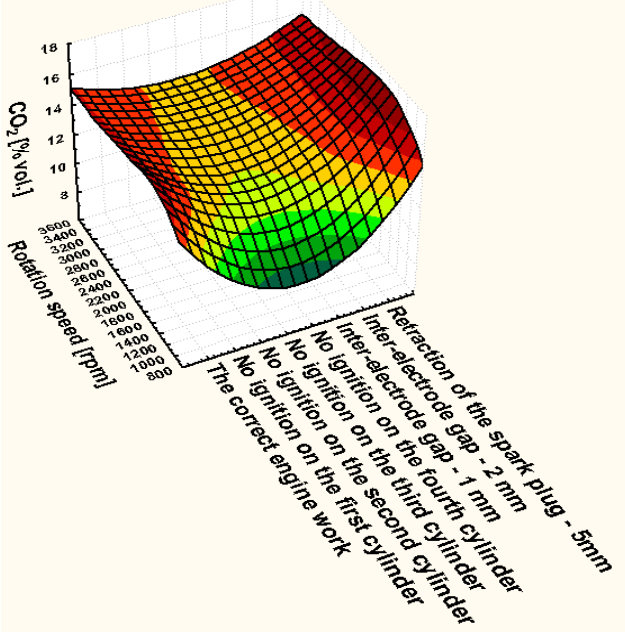

Fig. 24. The carbon dioxide content of the Fiat 1.1 petrol-powered engine

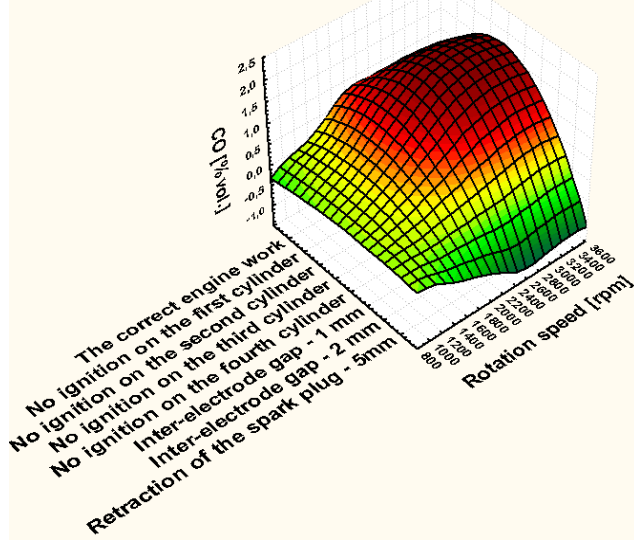

Fig. 25. The carbon monoxide content of the Fiat 1.1 petrol-powered engine

The emission of nitrogen oxides during the correct operation of the BMW engine increases with the increase of the rotational speed. During operation of the engine, 12 ppm nitrogen oxides are emitted at idle speed. For higher speeds from 3500-3600 rpm the emission rises to $35 \mathrm{ppm}$. Higher values of nitric oxide are achieved when working with an increased inter-electrode gap or offset spark plug. The greatest increase in the emission of nitrogen oxides is visible at the moment of switching off one of the spark plugs. It is twice as high in terms of correct engine operation.

The hydrocarbon emission during the correct engine operation for the whole range of rotational speeds is maintained at 400-500 ppm. Changing the inter-electrode gap or offsetting the spark plug causes emission of hydrocarbons emitted to the value of 1000-1500 ppm. After disconnecting the spark plug, the hydrocarbons increase by a factor of 3000-3500 ppm.

The carbon dioxide released remains at the level of $8 \%$ of the exhaust volume during idling. The concentration increases until the rotational speed reaches $2,800 \mathrm{rpm}$ and then remains constant at $12 \%$ of the exhaust volume. Increasing the inter-electrode gap or removing the spark plug causes a sharp decrease to $9 \%$ of the volume. Excluding 
only one of the spark plugs, the hydrocarbon concentration is maintained at the level of $6-7 \%$ of the gas volume.

The content of carbon monoxide in the exhaust gases gradually decreases as a function of the rotational speed and reaches its maximum value during idling. A smaller amount of carbon monoxide emitted is obtained by increasing the inter-electrode gap or removing the spark plug. Disconnecting one of the spark plugs causes a decrease in $\mathrm{CO}$ to $2-3 \%$ of the volume of the exhaust during idling and $1-2 \%$ for higher rotational speeds.

\section{Summary}

The mathematical model of the ignition system developed in the LabView software describes the change of the voltage value on the secondary winding of the ignition coil. It allows to analyse individual sections: sparking, transient and a short circuit of the reference high voltage waveform in relation to the voltage waveform of the simulated ignition system fault.
The tests carried out on the internal combustion engine with a spark ignition proved to what extent the toxicity of exhaust gases changes during simulation of typical ignition system failures. The most unfavourable effects of the engine's impact on the environment occurred during ignition losses, where in one of the cylinders there was no combustion. As a result, the hydrocarbon emission increased several times. By simulating a change in the inter-electrode gap or the removal of the electrode of the spark plug, large changes in the emission of nitrogen oxides and hydrocarbons were observed.

Summarising the analysis of the composition of toxic substances, the impact of damages on the operation of the engine fuelled with gasoline and gas in the content of toxic components was found. Using the EOBD on-board diagnostics and recorded runs of toxic components, a diagnostic database can be developed containing error codes and approximate emission rates.

\section{Bibliography}

[1] BRZOZOWSKA, L., BRZOZOWSKI, K., DRĄG Ł. Transport drogowy a jakość powietrza atmosferycznegomodelowanie komputerowe $\mathrm{w}$ mezoskali, Wydawnictwa Komunikacji i Łaczności, Warszawa 2009.

[2] CHŁOPEK, Z., Pojazdy samochodowe ochrona środowiska naturalnego, Wydawnictwa Komunikacji i Laczności, Warszawa 2002.

[3] CHŁOPEK, Z. Some remarks on engine testing in dynamic states, Combustion Engines. 2010, 143, 60-71.

[4] DZIUBIŃSKI, M. Ecological aspect of electronic ignition and electronic injection system. Environmental engineering V. 2017.

[5] DZIUBIŃSKI, M. Testing of exhaust emissions of vehicles combustion engines. Environmental engineering V. 2017.

[6] DZIUBIŃSKI, M., WALUSIAK, S. Symulacja pracy układu zapłonowego, Politechnika Lubelska. Lublin 1993.
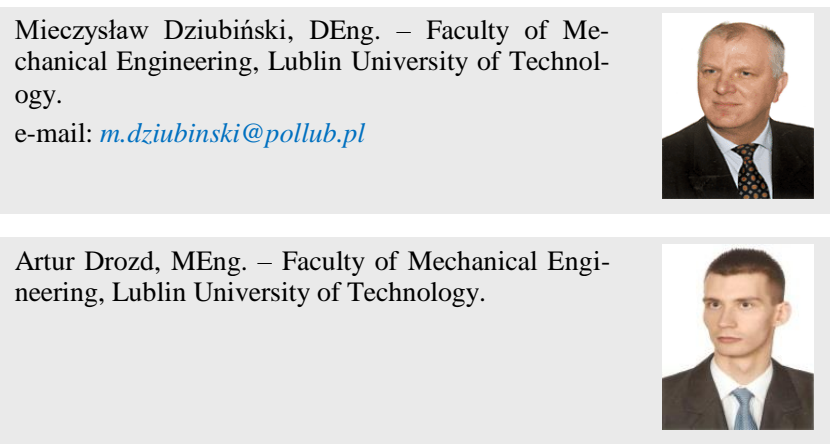

Adam Kiszczak, MEng. - Faculty of Mechanical Engineering, Lublin University of Technology

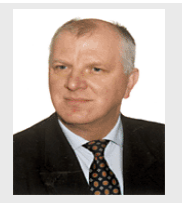

Ewa Siemionek, DEng. - Faculty of Mechanical Engineering, Lublin University of Technology.

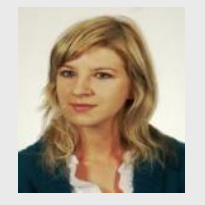

Michał Ścirka, MEng. - Faculty of Mechanical Engineering, Lublin University of Technology.

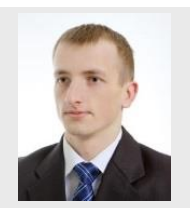

Krzysztof Sobota, MEng. - Faculty of Mechanical Engineering, Lublin University of Technology. 